\title{
SISTEMA DE INFORMAÇÃO: BENEFÍCIOS AUFERIDOS COM A IMPLANTAÇÃO DE UM SISTEMA WMS EM UM CENTRO DE DISTRIBUIÇÃO DO SETOR TÊXTIL EM NATAL/RN
}

\section{Hélio Roberto Hékis}

Doutor em Engenharia de Produção pela Universidade Federal de Santa Catarina - UFSC Professor da Universidade Federal do Rio Grande do Norte - UFRN hekis1963@gmail.com (Brasil)

\section{Lawrence Cézar Medeiros Araújo de Moura}

Bacharel em Engenharia de Produção pela Universidade Federal do Rio Grande do Norte - UFRN lawrence_nat@hotmail.com (Brasil)

\section{Ricardo Pires de Souza}

Mestre em Engenharia de Produção pela Universidade Federal do Rio Grande do Norte - UFRN Professor da Universidade Federal do Rio Grande do Norte - UFRN ripiso@gmail.com (Brasil)

\section{Ricardo Alexsandro de Medeiros Valentim}

Doutor em Engenharia Elétrica pela Universidade Federal do Rio Grande do Norte - UFRN Professor da Universidade Federal do Rio Grande do Norte - UFRN ricardo.valentim@ufrnet.br (Brasil)

\section{RESUMO}

Os sistemas de informações (SI) vêm sendo largamente utilizados nas organizações como vantagem competitiva, auxiliando os gestores em suas tomadas de decisão. Um dos SI que gerencia de forma eficiente e eficaz um centro de distribuição (CD) é denominado WMS (Warehouse Management System). O presente trabalho tem como objetivo geral descrever as melhorias advindas da implantação de um sistema de gerenciamento de $\mathrm{CD}$, tendo como foco a área de processamento de mercadorias em uma grande empresa do setor têxtil em Natal/RN. Associado ao objetivo geral, o estudo também pretende analisar o fluxo das mercadorias e analisar o sistema de informação gerencial atual da empresa estudada. Como resultados verificou-se a redução no lead time das mercadorias em $24 \%$, o aumento da produtividade dos funcionários e a melhora na gestão do $\mathrm{CD}$. Outro ponto de destaque foi a eliminação de locais predeterminados para as mercadorias, otimizando o processo e o deslocamento dos colaboradores.

Palavras-chave: Sistema de Informação Gerencial; WMS; Centro de Distribuição. 


\section{INTRODUÇÃO}

Com a abertura dos mercados e a globalização, a estabilidade econômico-financeira das organizações deixou de existir. Atualmente as empresas vivem em um ambiente altamente dinâmico e competitivo, tornando o controle de estoque eficiente indispensável para que as empresas se mantenham competitivas (Favaretto, 2012). Buscando alternativas na gestão de estoques, algumas empresas optaram pelo fornecimento de suas mercadorias via Centros de Distribuição (CD). Os CDs, assim como outras partes integrantes das organizações, necessitam evoluir, buscando a redução de custos, o acompanhamento de resultados, sempre com foco na satisfação dos clientes.

Uma das formas de evolução dos CDs pode ser propiciada com a implementação de sistemas de gerenciamento de armazéns, mais conhecidos como WMS (Warehouse Management System), os quais vieram para substituir os antigos sistemas que apenas gerenciavam as entradas e saídas de mercadorias dos depósitos. Essa evolução proporcionou o uso mais intensivo do conceito de armazenagem dinâmica ou aleatória, em que as mercadorias deixaram de ter locais fixos de armazenagem e passaram a ser estocadas em quaisquer locais disponíveis do depósito, pois esses locais foram devidamente identificados e cadastrados, sendo possível o seu controle por endereços. Assim, criou-se a possibilidade de aumentar a densidade de estocagem nos depósitos, pois a reserva de espaços físicos para o estoque máximo de cada item deixou de ser exigido. Com isso iniciou-se o trabalho com volumes referenciados no estoque médio dos itens.

O presente trabalho tem como objetivo geral demonstrar os principais benefícios aferidos após a implementação de um sistema de informação $(W M S)$ em uma das maiores empresas do setor têxtil do Rio Grande do Norte. Associado ao objetivo geral, o presente estudo pretende analisar o fluxo das mercadorias no CD e analisar o sistema de informação gerencial atual da empresa estudada.

O problema de pesquisa a ser avaliado consiste em verificar o funcionamento de um CD antes e depois da implantação de um sistema de informação WMS. A metodologia aplicada foi a pesquisa descritiva exploratória com abordagem qualitativa e quantitativa associada a um estudo de caso.

$\mathrm{O}$ artigo está estruturado em sete seções. Além desta seção introdutória que apresenta a estrutura do artigo; as seções 2 e 3 apresentam as sínteses da discussão teórica dos temas abordados; a seção 4 destaca os aspectos metodológicos; a seção 5 aborda o estudo de caso de uma empresa do setor têxtil; a seção 6 mostra os resultados alcançados. E por fim a seção 7 traz as conclusões, limitações e recomendações para futuros trabalhos.

Revista de Administração e Inovação, São Paulo, v. 10, n.4, p. 85-109, out./dez. 2013. 


\section{GESTÃO DA INFORMAÇÃO}

\subsection{Dados, informação, conhecimento}

Para Russo (2010), a definição do que é Dado, Informação e Conhecimento merece grande reflexão, visto que os seus significados não são tão bem distintos, e por vezes pode haver confusão em duas definições pela proximidade em que se encontram. $\mathrm{O}$ autor argumenta, ainda, que os termos dados, informação e conhecimento constituem um elemento básico para o processo de comunicação dentro das organizações, os quais são necessários no apoio à tomada de decisão.

Davenport e Prusak (2003) afirmam que é preciso frisar que dados, informação e conhecimento não são sinônimos. E que o sucesso ou o fracasso de uma organização pode ter grande dependência de se saber de qual deles precisamos, com qual deles estamos lidando e o que é possível ou não se fazer com cada um deles.

Ainda segundo Davenport e Prusak (2003), os dados não têm significado inerente, eles apenas descrevem parte daquilo que aconteceu, não fornecendo julgamento nem interpretação e ainda não fornecem qualquer base sustentável para uma tomada de decisão efetiva. Reforçando essa perspectiva, Silva (2010) afirma que o dado é algo apenas que se observa, possuindo valor e atributo, porém nada mais que isso.

Já o termo informação é descrito na visão de Davenport e Prusak (2003) como uma mensagem, que se apresenta geralmente na forma de um documento ou mesmo uma comunicação audível ou visível. A partir do momento em que o dado é acrescido de significado ele se transforma em informação, essa transformação agrega valor ao dado. Silva (2010) reforça essa ideia ao afirmar que a informação é gerada a partir de um único dado ou de um conjunto deles.

Todas as empresas necessitam de informações relevantes que suportem as suas decisões gerenciais e, segundo Ackoff (1967 apud Oliveira, 1999, p. 21), foi observado que, apesar dessa necessidade de informações por parte dos gestores, eles são vítimas da abundância de informações irrelevantes. Oliveira (1999, p. 29) destaca ainda que as informações são importantes fontes de redução de incertezas do ambiente, desde que estas sejam informações relevantes e alinhadas com as estratégias da empresa.

Nesse sentido, Silva, Souza e Hékis. (2011) salientam que a informação tem importância fundamental em uma organização. Associada a um processo, a informação é o insumo que pode atribuir a qualidade necessária às tomadas de decisão e dessa maneira trazer resultados positivos com o alcance dos objetivos traçados.

Revista de Administração e Inovação, São Paulo, v. 10, n.4, p.85-109, out./dez. 2013. 
O Quadro 1 apresenta um comparativo no qual pode-se obter uma compreensão a partir dos significados de dados, informação e conhecimento mostrados pelos autores.

\begin{tabular}{|c|c|c|}
\hline Dados & Informação & Conhecimento \\
\hline $\begin{array}{ll}\checkmark & \text { Simples observações } \\
& \text { sobre o estado do } \\
& \text { mundo } \\
\checkmark & \text { Facilmente estruturado } \\
\checkmark & \text { Facilmente obtido por } \\
& \text { máquinas } \\
\checkmark & \text { Frequentemente } \\
& \text { quantificado } \\
\checkmark & \text { Facilmente transferível }\end{array}$ & $\begin{array}{ll}\checkmark & \begin{array}{l}\text { Dados dotados de } \\
\text { relevância e propósito }\end{array} \\
\checkmark & \text { Requer unidade de } \\
& \text { análise } \\
\checkmark & \text { Exige consenso em } \\
\text { relação ao significado } & \\
\checkmark & \text { Exige necessariamente } \\
& \text { a medição humana }\end{array}$ & $\begin{array}{ll}\checkmark & \text { Informação valiosa da } \\
& \text { mente humana } \\
\checkmark & \text { Inclui reflexão, síntese } \\
& \text { e contexto } \\
\checkmark & \text { De difícil estruturação } \\
\checkmark & \text { De difícil captura em } \\
& \text { máquinas } \\
\checkmark & \text { Frequentemente tácito } \\
\checkmark & \text { De difícil transferência }\end{array}$ \\
\hline
\end{tabular}

Quadro 1: Dados, informação e conhecimento.

Fonte: Davenport e Prusak (2002, p.18).

\subsection{Sistemas de Informação}

Na visão de Siqueira (2005), a real necessidade da implantação de um sistema que colete, armazene, processe e distribua a informação na organização se dá pela importância da obtenção da informação com qualidade, agilidade e em tempo hábil, para que esta venha se tornar uma fonte de conhecimento. Esses sistemas são chamados genericamente de Sistemas de Informação (SI).

Para Siqueira (2005, p. 3), os sistemas são definidos genericamente como "um conjunto de elementos interdependentes e interagentes que formam um todo organizado e tem por finalidade transformar entradas em saídas". O mesmo autor ainda apresenta em seus estudos uma representação básica de um sistema, demonstrado na Figura 1.

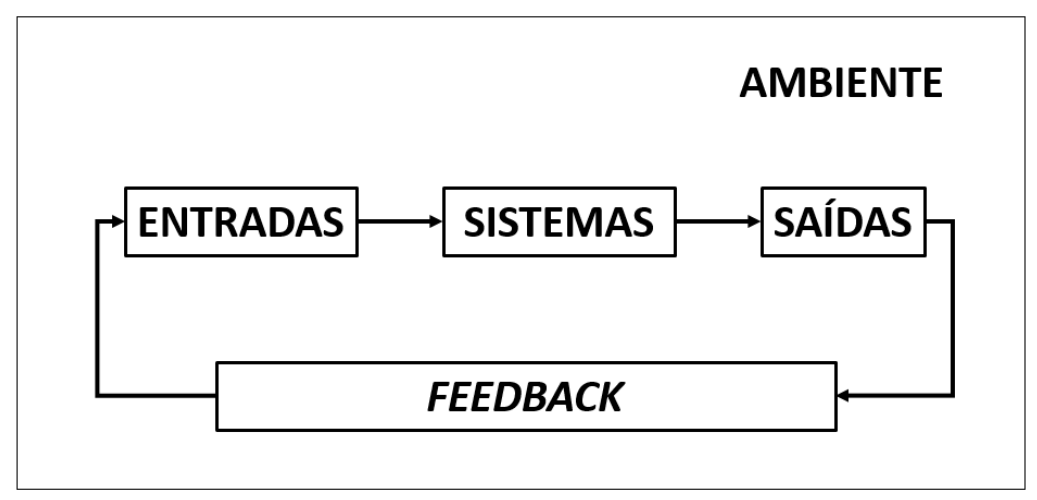

Figura 1 - Esquema básico de um sistema.

Fonte: Adaptado de Siqueira (2005, p. 3). 
Segundo Barbosa e Almeida (2002), os SI são ferramentas que estão voltadas para apoiar os processos de organização, controle, tomada de decisão e aquisição de conhecimento nas empresas. Ainda segundo esses autores, os SI utilizam os computadores para apoiar o processamento ágil de dados, a geração, o registro, acesso e difusão das informações no meio organizacional, apresentando-se assim como uma importante ferramenta inserida no contexto das constantes mudanças em que se encontram os setores da nossa sociedade.

Para Karim (2011), SI são arranjos de grupos, dados, processos e tecnologias, que atuam em conjunto para coletar, processar, armazenar e distribuir informações para melhorar e agilizar o processo de tomada de decisão. Sendo assim, de acordo com esse autor, a importância de um SI se dá principalmente por fornecer informações mais precisas e ágeis para que as decisões sejam embasadas de forma mais eficaz.

De acordo com Laudon e Laudon (2007), um dos objetivos de se implantar um SI em uma empresa é o aperfeiçoamento na tomada de decisão por parte dos administradores, que utilizam dados reais, os quais podem ser proporcionados pelos SI. Já Kamaruddin, Razali e Deraman (2011) afirmam que os SI buscam aprimorar as tomadas de decisão, pois utilizam várias informações como suporte. Assim sendo, esses sistemas são ferramentas-chave para uma melhor tomada de decisão, já que os gestores terão maior capacidade analítica sobre os problemas.

Para Leal, Fleming, Shinzato, Soares e Moretti (2010), é necessário a implantação de um SI que seja utilizado para o tratamento das informações, para que estas possam ser oferecidas com prontidão e qualidade às pessoas que vão utilizá-la, no entanto as informações devem ser relevantes para que assim possam ser utilizadas em sua totalidade. De acordo com Rezende (2005), qualquer sistema, seja ele usuário ou não de tecnologias da informação, que armazena dados e gera informações pode ser considerado de forma genérica um SI.

Um SI pode ser definido tecnicamente como:

Um conjunto de componentes inter-relacionados que coletam (ou recuperam), processam, armazenam e distribuem informações destinadas a apoiar a tomada de decisões, a coordenação e o controle de uma organização. Além de dar apoio à tomada de decisões, à coordenação e ao controle, esses sistemas também auxiliam os gerentes e trabalhadores a analisar problemas, visualizar assuntos complexos e criar novos produtos (Laudon \& Laudon, 2007, p. 9).

Kahraman, Kaya e Çevikcan (2011) elucidam que a tomada de decisão é uma das tarefas mais importantes dos gestores de uma organização e é geralmente baseada em diversas fontes de dados contidos em vários SI. Dessa forma pode-se observar que a tomada de decisão é tarefa de fundamental 
importância para os gestores de uma organização e esta é suportada pelos SI que os auxiliam. Por serem decisões de alto nível gerencial e que afetam fortemente a empresa, esses sistemas proporcionam uma tomada de decisão mais precisa, uma vez que os gestores têm a capacidade de analisar os problemas por diversos ângulos, com informações mais precisas, oportunas e relevantes.

\subsection{Sistemas de Informações Gerenciais (SIG)}

De acordo com Carmo e Pontes (1999), a alta competitividade dos mercados vem trazendo mudanças significativas no ambiente externo e interno das empresas, exigindo tomadas de decisões mais rápidas, sendo os recursos de informática ferramentas de suma importância para o planejamento, coordenação e controle da empresa. Ainda segundo esses dois autores, um dos fatores que determinam o diferencial entre as empresas, no cenário atual, é a forma como estas utilizam as informações.

De acordo com Oliveira (2009), as informações que sustentam o processo de tomada de decisão dos executivos de uma organização, quando consolidadas em documentos de forma estruturada, dão origem aos conhecidos relatórios gerenciais. Ainda segundo esse autor, a interligação dos processos administrativos com os relatórios gerenciais é sustentada por um adequado SIG:

Sistema de informações gerenciais (SIG) é o processo de transformação de dados em informações que são utilizadas na estrutura decisória da empresa, bem como proporcionam a sustentação administrativa para otimizar os resultados esperados da empresa (Oliveira, 2009, p. 235).

Na mesma linha de pensamento, Laudon e Laudon (2007) afirmam que o SIG proporciona relatórios referentes ao desempenho corrente da organização. Com essa informação, é possível monitorar e controlar a empresa, além de prever seu desempenho futuro. Os SIGs usualmente atendem aos gerentes interessados em resultados semanais, mensais e anuais, embora alguns deles permitam detalhar os dados em base diária ou horária, se necessário.

Ajayi e Omirin (2007) ressaltam que um SIG é basicamente focado na coleta, no processamento, armazenamento e transmissão de informações relevantes que apoiem a operação de gestão das organizações. Ainda segundo esses autores, o sucesso na tomada de decisão é altamente dependente, em parte das informações disponíveis e em parte das funções que são os componentes do processo. Os autores apontam, por exemplo, que se os objetivos gerenciais não estão claros ou não existem, por possível falta de informação adequada, então não existe uma base para pesquisa das possíveis decisões que podem ser tomadas. Sem informações obtidas em uma pesquisa, não há

Revista de Administração e Inovação, São Paulo, v. 10, n.4, p. 85-109, out./dez. 2013. 
alternativas a serem comparadas, e sem nenhuma comparação entre alternativas a escolha de um determinado curso de ação pode levar a resultados não desejados.

Stair e Reynolds (2002) salientam que um SIG tem como propósito primário apoiar as empresas a atingir suas metas, fornecendo aos gerentes detalhes referentes às operações regulares dessas empresas, de maneira que eles possam planejar, controlar e organizar com mais efetividade e eficiência. Ainda segundo esses autores, o SIG tem a capacidade de prover a esses gerentes não só informação e suporte para uma tomada de decisão efetiva, mas também as respostas para as operações do dia a dia e dessa forma agregar valor aos processos da organização.

Nesse sentido Batista (2004, p. 22) define que SIG é:

O conjunto de tecnologias que disponibilizam os meios necessários à operação do processo decisório em qualquer organização por meio do processamento dos dados disponíveis. É um sistema voltado para a coleta, armazenagem, recuperação e processamento de informações usadas ou desejadas por um ou mais executivos no desempenho de suas atividades. É o processo de transformação de dados em informações que são utilizadas na estrutura decisória da empresa e proporcionam a sustentação administrativa para otimizar os resultados esperados.

Karim (2011) afirma que os SIGs são considerados sistemas integrados de usuários-máquinas, os quais fornecem informações para operações de apoio, gestão e tomada de decisão em diversos níveis de uma organização. Ainda segundo Karim (2011), as organizações estão tentando aumentar seus níveis de agilidade, melhorando o processo decisório para que assim possam ser mais eficientes e assim atenderem às sucessivas flutuações do mercado. Para tanto, as empresas de médio e grande porte estão se preocupando em fazer um ciclo de investimentos em componentes mais modernos de SIG.

Os SIGs estão interconectados com outros diversos sistemas de informação. A Figura 2 demonstra o posicionamento de um SIG em meio aos outros sistemas de informação. 


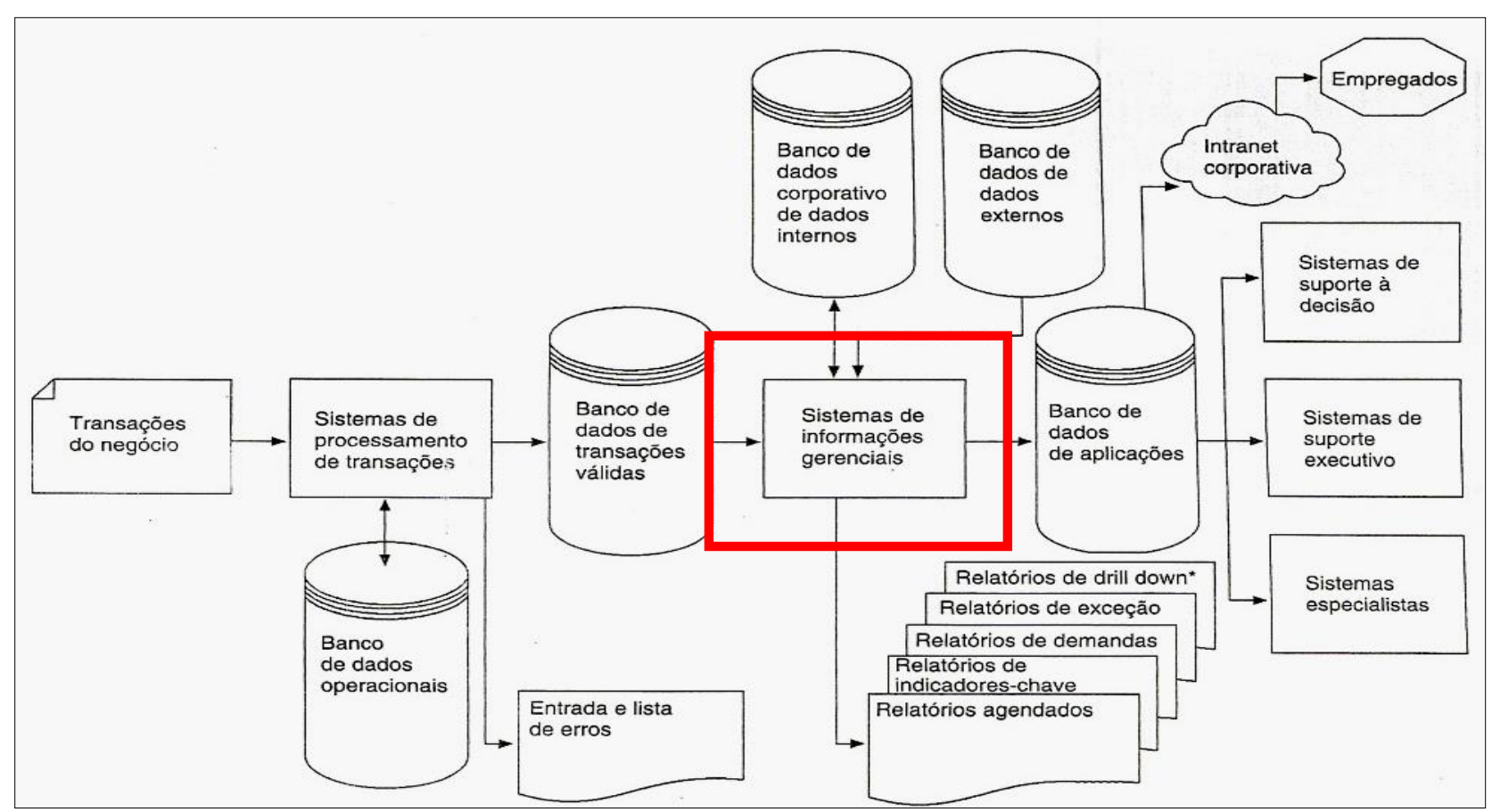

Figura 2 - Fontes de Informações Gerenciais.

Fonte: Stair e Reynolds (2002, p. 279).

\subsection{Enterprise Resource Planning (ERP) ou Sistemas Integrados de Gestão Empresarial}

O acelerado desenvolvimento de novas tecnologias em conjunto com a utilização de modelos de gestão integrada e de novos métodos de fabricação tem propiciado que as empresas contornem certos trade offs (Machado \& Moraes, 2011). No ambiente de negócios altamente competitivo da atualidade, as organizações passam cada vez mais a depender da Tecnologia da Informação (TI).

A integração entre os diversos departamentos existentes nas organizações vem se tornando uma tendência popular nos negócios nos últimos anos (Tsai, 2008). Ainda de acordo com Tsai (2008), o sistema ERP oferece não somente a articulação e integração das várias camadas no sistema, mas também diminui os custos e o tempo do procedimento de troca de dados.

Para Colangelo Filho (2001), a noção-chave para a definição de ERP é integração. Ainda segundo esse autor, o sistema ERP é um sistema que permite às empresas:

\footnotetext{
$\checkmark \quad$ Integrar e automatizar parcela de seus processos de negócios, abrangendo áreas como finanças, controles, logística e recursos humanos;

$\checkmark$ Compartilhar dados e também uniformizar os processos de negócios;

$\checkmark$ Produzir e também utilizar informações em tempo real.
}

Revista de Administração e Inovação, São Paulo, v. 10, n.4, p. 85-109, out./dez. 2013. 
Souza (2000, p. 11) afirma que os sistemas ERP podem ser definidos como:

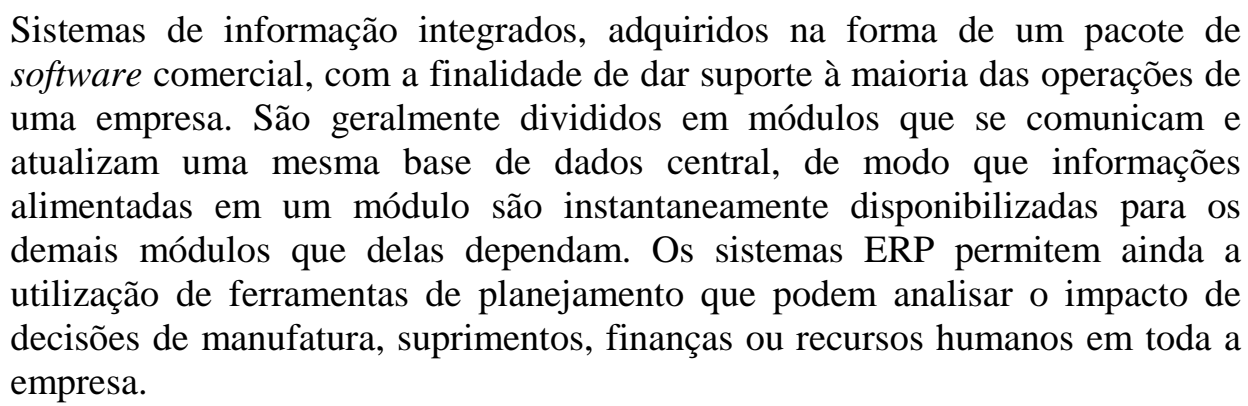

Garcia et al. (2009) afirmam que os sistemas ERP foram amplamente adotados por grandes e médias empresas a partir da década de 90 e passaram a fazer parte de suas estratégias, por esse motivo o processo decisório sobre a implantação desse sistema veio a se tornar bastante complexo e delicado.

Davenport (1998) afirma que os sistemas ERP são pacotes de sistemas que prometem a integração das informações que fluem pela empresa, informações estas que podem ser financeiras e contábeis, de recursos humanos, da cadeia de suprimentos e dos clientes. Esses sistemas impõem em uma empresa, organização e cultura a sua própria lógica. Quando novas informações são inseridas no sistema, informações relacionadas a elas são atualizadas automaticamente. Sistemas ERP otimizam o fluxo de dados de uma organização e proporcionam uma gestão com acesso direto a uma grande quantidade de informações em tempo real, resultando em um grande ganho de produtividade para as empresas.

Existem diversas áreas de aplicação dos sistemas ERP, pois esses sistemas têm como objetivo integrar as diversas áreas de uma empresa, assim o Quadro 2 demonstra as principais áreas de aplicação dos sistemas ERP.

Revista de Administração e Inovação, São Paulo, v. 10, n.4, p.85-109, out./dez. 2013. 


\begin{tabular}{|l|l|c|}
\hline Finanças e controles & Operações/Logística & Recursos Humanos \\
\hline$\checkmark$ Contabilidade & $\checkmark$ Suprimentos & $\checkmark$ Recrutamento e \\
Financeira & $\checkmark$ Administração de & seleção de pessoal \\
$\checkmark$ Contas a pagar & materiais & $\checkmark$ Treinamento \\
$\checkmark$ Contas a receber & $\checkmark$ Gestão da qualidade & $\checkmark$ Benefícios \\
$\checkmark$ Tesouraria & $\checkmark$ Planejamento e & $\checkmark$ Desenvolvimento de \\
$\checkmark$ Ativo imobilizado & controle da produção & pessoal \\
$\checkmark$ Orçamentos & $\checkmark$ Custos de produção & $\checkmark$ Medicina e segurança \\
$\checkmark$ Contabilidade & $\checkmark$ Previsão de vendas & do trabalho \\
gerencial & $\checkmark$ Entrada de pedidos & $\checkmark$ Remuneração \\
$\checkmark$ Custos & $\checkmark$ Faturamento & (salários) \\
$\checkmark$ Análise de & $\checkmark$ Fiscal & $\checkmark$ Folha de Pagamento \\
rentabilidade & $\checkmark$ Gestão de projetos & \\
& & \\
\hline
\end{tabular}

Quadro 2 - Áreas de aplicação dos sistemas ERP.

Fonte: Colangelo Filho (2001, p. 19).

Segundo Souza (2000), mesmo que os conceitos utilizados em sistemas ERP possam ser usados por algumas empresas que queiram desenvolver os seus aplicativos internamente, o termo que caracteriza um sistema ERP refere-se basicamente aos pacotes adquiridos pelas organizações. Alguns exemplos de sistemas ERP que podem ser encontrados no mercado são o Oracle Financials da empresa americana Oracle, Baan IV proveniente da empresa holandesa Baan e um dos mais conhecidos o R/3 da empresa alemã SAP.

Na Figura 3 é apresentado um esquema que demonstra como um sistema ERP pode funcionar. Davenport (1998) afirma que no centro de um sistema ERP está um banco de dados que recebe e fornece dados para aplicativos que dão suporte às atividades de uma empresa. E graças à utilização de um banco de dados central, o fluxo de informações se torna drasticamente mais ágil. 


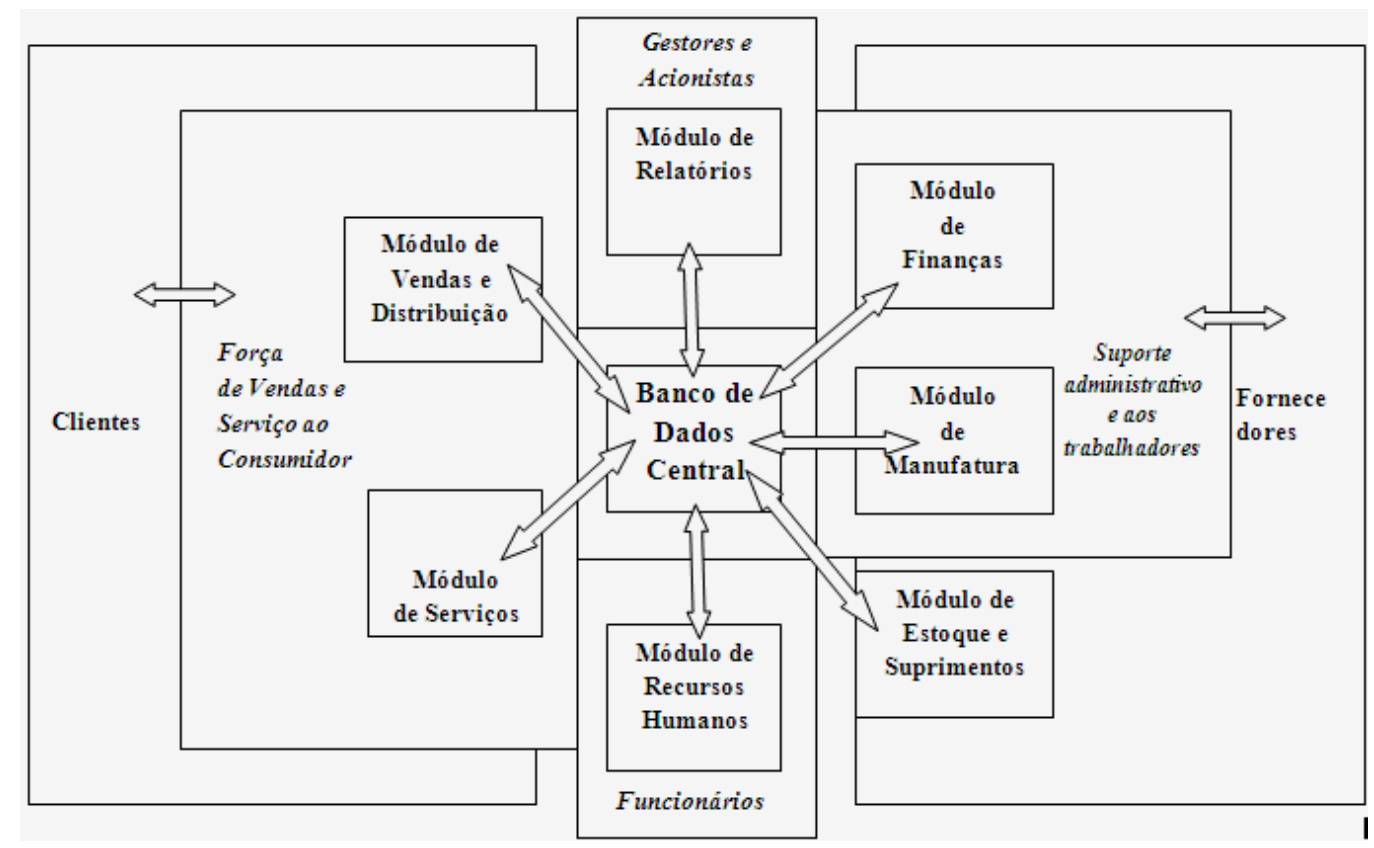

Figura 3 - Arquitetura de um sistema ERP. Fonte: Adaptado de Davenport (1998, p. 124).

Para Slack, Chambers e Johnston (2009), os sistemas ERP conseguem fazer com que todas as decisões e bases de dados provenientes de uma organização possam ser integrados, para que assim as decisões tomadas em uma parte da empresa possam ser refletidas no restante da organização.

O principal motivo dos sistemas ERP terem ganhado espaço mundialmente no mercado foi o fato de tais sistemas integrarem as atividades da organização, quando estas eram visualizadas como processos. Pode-se constatar que uma das principais motivações das organizações para implantar um sistema ERP é a integração das informações que fluem pela empresa, que assim podem melhorar a qualidade e a agilidade das tomadas de decisões (Tsai, 2008; Colangelo Filho, 2001; Davenport, 1998, Slack et al.,2009; Garcia, Freitas, Glugovskis \& Albuquerque, 2009).

As atividades de sistemas são os responsáveis pelo desempenho inovador no setor de Tecnologia de Informação e Comunicação (Stal \& Morganti, 2011). Para Turban, McLean e Wetherbe (2004), o programa que é líder entre os sistemas ERP é o R/3 da empresa alemã SAP. Corroborando, Slack et al. (2009) afirmam que a maior empresa fornecedora de programa de sistemas de ERP foi a empresa alemã SAP.

O sistema SAP ERP é um programa integrado de planejamento de recursos corporativos, de qualidade mundialmente reconhecida, destinado a atender aos principais requisitos de software das mais exigentes empresas de médio e grande porte, de todos os setores e mercados verticais, em qualquer país do mundo (www.sap.com/brazil).

Revista de Administração e Inovação, São Paulo, v. 10, n.4, p.85-109, out./dez. 2013. 
Entretanto, ainda segundo Turban et al. (2004), um dos problemas existentes na implantação do SAP e de outros softwares de ERP é sua grande complexidade, há casos em que as empresas necessitam mudar processos de negócio existentes na corporação para adaptar-se à formatação do SAP. Por esses e outros motivos, é que muitas empresas desconsideram o SAP como solução ótima para seus problemas.

\section{CENTROS DE DISTRIBUIÇÃO}

Um dos grandes desafios da logística é a distribuição física de produtos. Por esse motivo, o gerenciamento logístico é observado como questão básica na estruturação de sistemas de distribuição, para que estes sejam capazes de atender, a um menor custo, os mercados que estejam situados geograficamente mais distantes dos centros produtores, oferecendo um nível de serviço cada vez maior no que tange à disponibilidade de estoque e tempo de atendimento (Lacerda, 2000).

De acordo com Rodrigues e Pizzolato (2003), as empresas tendem a melhorar cada vez mais o fluxo de materiais na cadeia de suprimentos, visando à diminuição do tempo entre o recebimento e a entrega dos pedidos, para que o investimento em estoque seja reduzido, já que este é um custo que não agrega valor ao produto. Ainda segundo esses autores, o objetivo da armazenagem em Centros de Distribuição $(\mathrm{CD})$ está voltado ao provimento de uma capacidade de resposta mais rápida e à redução das necessidades de estoques. O mercado acompanha esse foco, na medida em que migra para a centralização de estoques, facilitando assim a entrega direta e contínua em cada ponto de venda. Dessa forma o CD assume uma posição de grande importância logística.

Segundo Lacerda (2000, p. 30), os centros de distribuição são:

[...] típicos de sistemas de distribuição escalonados, onde o estoque é posicionado em vários elos de uma cadeia de suprimentos. Seu objetivo é permitir rápido atendimento às necessidades dos clientes de uma determinada área geográfica distante dos centros produtores. Para prover utilidade no tempo, avançam-se os estoques para um ponto próximo aos clientes e os pedidos são então atendidos por este centro avançado, a partir do seu próprio estoque.

Para Rodrigues e Pizzolato (2003, p. 1), “o CD é uma configuração regional de armazém onde são recebidas cargas consolidadas de diversos fornecedores. Essas cargas são fracionadas a fim de agrupar os produtos em quantidade e sortimento corretos, e então encaminhados para os pontos de venda".

Revista de Administração e Inovação, São Paulo, v. 10, n.4, p. 85-109, out./dez. 2013. 
A utilização de estruturas como os CDs permitem que haja o recebimento de cargas consolidadas que são movimentadas por grandes distâncias, diminuindo os custos com transporte. As possíveis cargas fracionadas que são levadas até os clientes são feitas em menores distâncias. A Figura 4 demonstra de forma simplificada o funcionamento de um centro de distribuição.

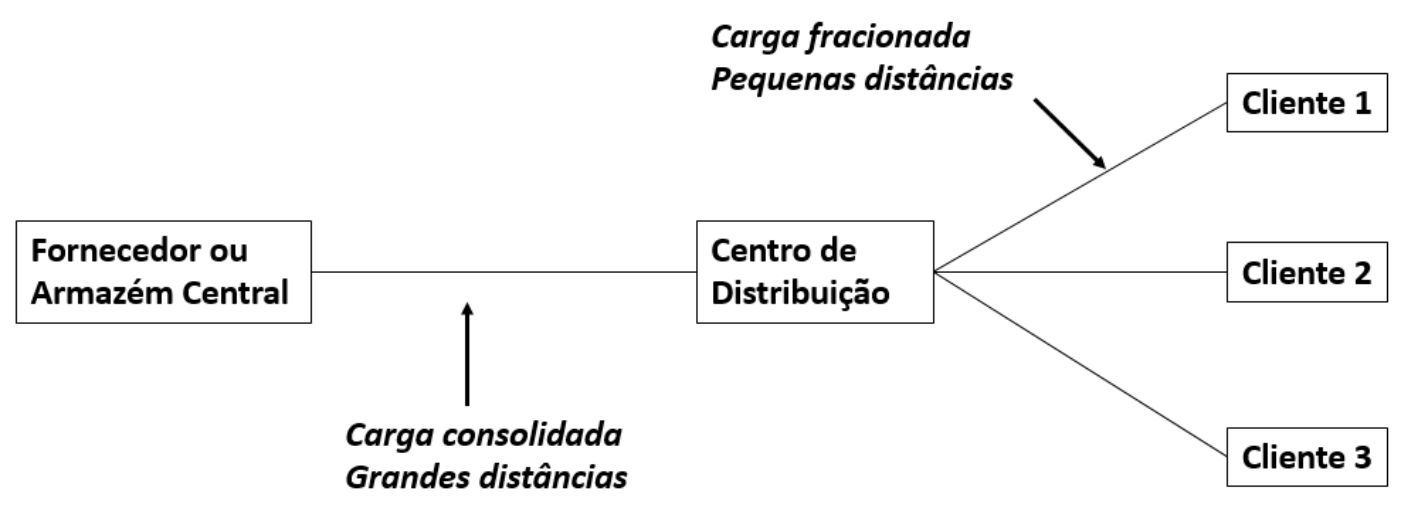

Figura 4 - Esquema de funcionamento de um centro de distribuição.

Fonte: Adaptado de Lacerda (2000).

Segundo Lacerda (2000), os CDs representam uma grande vantagem para os clientes que recebem de uma única vez (um único carregamento) os pedidos que foram efetuados em diversos fornecedores. Nesse sentido, os custos com transporte diminuem, uma vez que as cargas que saem dos CDs são consolidadas.

É possível observar que a utilização de CDs para movimentação de mercadorias em uma cadeia de suprimentos é bastante interessante, visto que há uma diminuição nos custos de transportes, por causa da consolidação das cargas, custos estes que representam grande parte do custo logístico total. Outro ponto positivo em se utilizar os CDs é que a quantidade de contatos entre fornecedor e clientes diminui, já que o CD irá funcionar como elo entre os fornecedores e os clientes, em que as mercadorias serão destinadas dos fornecedores ao centro de distribuição e este ficará encarregado de distribuir as mercadorias aos clientes (Lacerda, 2000; Rodrigues \& Pizzolato, 2003).

Para que sejam gerenciadas de forma eficiente e eficaz, essas estruturas de armazenagem e movimentação de materiais, os CDs, têm de ser corretamente gerenciadas e monitoradas. Para essa finalidade foram então desenvolvidos os sistemas de gerenciamento de armazéns, também conhecidos como WMS.

Revista de Administração e Inovação, São Paulo, v. 10, n.4, p.85-109, out./dez. 2013. 
Segundo Ma e Liu (2011) o investimento das empresas em sistemas de informações que gerenciem CDs, como o WMS, pode ajudar a empresa a diminuir os custos operacionais e colocá-la em uma posição dominante no mercado. Estabelecendo o uso de sistemas de informação como o WMS, as informações podem ser distribuídas dentro da empresa, entre os funcionários, de forma mais ágil e sem deficiência, beneficiando a empresa com o controle e diminuição dos estoques, melhorando o volume de negócios e reduzindo os custos, abrangendo também os custos com recursos humanos.

Para Banzato (2011), um sistema WMS é:

[...]um sistema de gestão por software que melhora as operações do armazém através do eficiente gerenciamento de informações e conclusão das tarefas com um alto nível de controle e acuracidade do inventário. As informações gerenciadas são derivadas de transportadoras, fabricantes, sistema de informações de negócios, clientes e fornecedores. O WMS utiliza estas informações para receber, inspecionar, estocar, separar, embalar e expedir mercadorias da forma mais eficiente. A eficiência é obtida através do planejamento, roteirização e tarefas múltiplas dos diversos processos do armazém.

Tan e Dong (2011) afirmam que os sistemas de gestão de armazéns, ou sistemas WMS, é um sistema de gestão de materiais utilizado principalmente por empresas modernas. Ele pode ser utilizado para gerenciamento de armazéns únicos ou locais, como também pode ser utilizado para gerenciar múltiplos armazéns distantes geograficamente. Esses sistemas tornam o ambiente empresarial mais dinâmico, desde o recebimento, passando pelo armazenamento até a saída do material, tornando possível estabelecer uma fácil interface entre o sistema e o usuário.

Para Sucupira (2004), o surgimento do WMS foi em razão da necessidade de melhorar os fluxos de informação e de materiais dentro de um armazém, tendo como resultados principais a redução de custos, a melhoria na operação e o aumento do nível de serviço prestado aos clientes. A otimização proporcionada pelo sistema $W M S$ faz com que haja um aumento da precisão das informações do estoque, da velocidade e qualidade das operações dentro do $\mathrm{CD}$ e da produtividade do pessoal e dos equipamentos utilizados nos processos. Os eventos ocorridos dentro do CD são registrados em tempo real, identificando o operador ou equipamento que realizou a tarefa. Isso se tornou possível por causa do surgimento de novas tecnologias de informação tanto em hardware quanto em software.

O WMS é um sistema que pode otimizar todas as atividades, tanto no âmbito operacional como no âmbito administrativo do processo de armazenagem dinâmica, tais como o recebimento, a inspeção, o endereçamento, a estocagem, a separação, a embalagem, o carregamento, a expedição, a emissão de documentos e inventários. A redução dos custos e o melhoramento dos serviços aos clientes são 
obtidos com a implantação e utilização de tais sistemas, já que a produtividade operacional tende a aumentar (Ribeiro; Silva \& Benvenuto, 2006). Ainda segundo esses autores, os sistemas WMS operam em tempo real interligados entre múltiplos armazéns, possibilitando assim a visualização da posição das mercadorias no local ou à distância. Esses sistemas também fazem rotinas de otimização que orientam o remanejamento de mercadorias, para que seja facilitada a estocagem e retirada dessas mercadorias, em função do giro dos produtos.

Para Banzato (2011), a partir da implantação de sistemas WMS, o negócio pode melhorar em duas importantes perspectivas. A primeira é a redução dos custos e a segunda é a melhora na qualidade dos serviços proporcionados ao cliente. A redução de custo é conseguida a partir da melhoria da eficiência da mão de obra, resultando num CD que exige uma menor carga de trabalho.

As melhorias observadas com mais frequência são relacionadas à diminuição da necessidade de horas extras, de contratação de pessoal, à medida que a empresa cresce. Uma das grandes vantagens de se ter um ambiente coberto por um WMS em tempo real é que os erros cometidos são imediatamente descobertos e corrigidos, evitando falhas nos processos (Banzato, 2011).

Os principais objetivos de um WMS são aumentar a precisão das informações de estoque, a velocidade e qualidade das operações dos centros de distribuição e a produtividade do pessoal e dos equipamentos dos depósitos. Entre suas características básicas, destacam-se a facilidade de acoplamento com sistemas ERP de mercado ou desenvolvidos internamente, a possibilidade de administrar múltiplos locais de estocagem, a possibilidade de administrar mercadorias de diferentes proprietários, a utilização de sistemas de coletas de dados por radiofrequência, e a utilização do conceito de convocação ativa (Sucupira, 2004).

\section{METODOLOGIA}

O presente estudo é apoiado por uma abordagem qualitativa e quantitativa, na medida em que são analisados dados provenientes de entrevistas e dados documentais provenientes do sistema da empresa em estudo.

De acordo com Denzin e Lincoln (2006, p. 390), "A pesquisa qualitativa é um campo interdisciplinar, transdisciplinar e, às vezes, contra disciplinar que atravessa as humanidades, as ciências sociais e as ciências físicas". A pesquisa quantitativa torna-se diferente da qualitativa, pois um erro no questionário observado após a aplicação pode inviabilizar o resultado. A classificação da pesquisa, levando em conta os objetivos, tem caráter descritivo exploratório, pois busca conhecer 
melhor o objeto a ser investigado e levantar opiniões, atitudes e crenças de uma população (Gil, 2009).

A unidade escolhida para estudo é um centro de distribuição de uma empresa do ramo têxtil situado na cidade de Natal/RN, por se tratar de uma empresa de grande porte e pelo fato de o pesquisador ter total acesso aos dados da organização.

Como técnicas para coleta de dados foram realizadas entrevistas não estruturadas com o gerente do $\mathrm{CD}$, como também foram efetuadas análises documentais das mercadorias que passaram pelo CD no período de março/2011 a outubro/2011, através dos dados gerados pelo sistema $W M S$ e disponíveis em seu banco de dados. Essas entrevistas foram documentadas de forma escrita.

\section{ESTUDO DE CASO: EMPRESA ALPHA}

A empresa em estudo encontra-se no centro de uma cadeia de suprimentos de uma das maiores empresas de confecção da América Latina. O centro de distribuição desta empresa faz a ponte entre as fábricas e as lojas pertencentes ao grupo. O CD em análise situa-se na cidade de Natal no estado do Rio Grande do Norte. A estrutura desse centro é de aproximadamente $33.000 \mathrm{~m}^{2}$, com a participação de mais de 700 colaboradores. O CD de Natal tem cerca de dez anos de existência, e foi um passo muito importante para o sucesso do grupo. Além do CD em estudo, existem mais outros dois centros de distribuição localizados na região Sudeste e na região Norte.

Atualmente o principal sistema de informações utilizado pela empresa é o sistema alemão SAP, que integra desde as fábricas, passando pelos CDs, até os pontos de venda, o que torna a informação muito mais segura e ágil através de toda a cadeia de suprimentos. Para complementar e facilitar a gestão da informação e a tomada de decisão nos centros de distribuição foi implantado recentemente o sistema WMS, sistema este mais simples e prático de utilizar do que o SAP.

O centro de distribuição em estudo é dividido em áreas, as quais são monitoradas e gerenciadas por seus líderes, encarregados e supervisores. As mercadorias ao chegarem das fábricas do grupo ou de fornecedores terceirizados entram no CD pela área de recebimento e é essa fase em que a mercadoria entra física e sistemicamente no ambiente que está sendo estudada. Após ser totalmente conferida no recebimento, a mercadoria passa para a etapa seguinte, a de processamento, cujo principal objetivo é colocar etiqueta de preço, cabide e embalagens para a mercadoria seguir para a etapa seguinte, a armazenagem. Na área de armazenagem, a mercadoria será estocada até o momento de sua retirada para seguir para a loja (ponto de venda). Essa área de armazenagem tem capacidade para estocar cerca

Revista de Administração e Inovação, São Paulo, v. 10, n.4, p. 85-109, out./dez. 2013. 
de 6 milhões de peças. Por fim, após a mercadoria ser alocada para uma filial, ela é retirada da armazenagem e segue para a área de expedição, de onde será enviada até o ponto de venda.

O fluxo das mercadorias pelo CD se dá em forma de "U", formato este que facilita a troca de informações e o contato entre os setores, o que torna a tomada de decisão mais fácil. O fluxo do CD pode ser analisado na Figura 5.

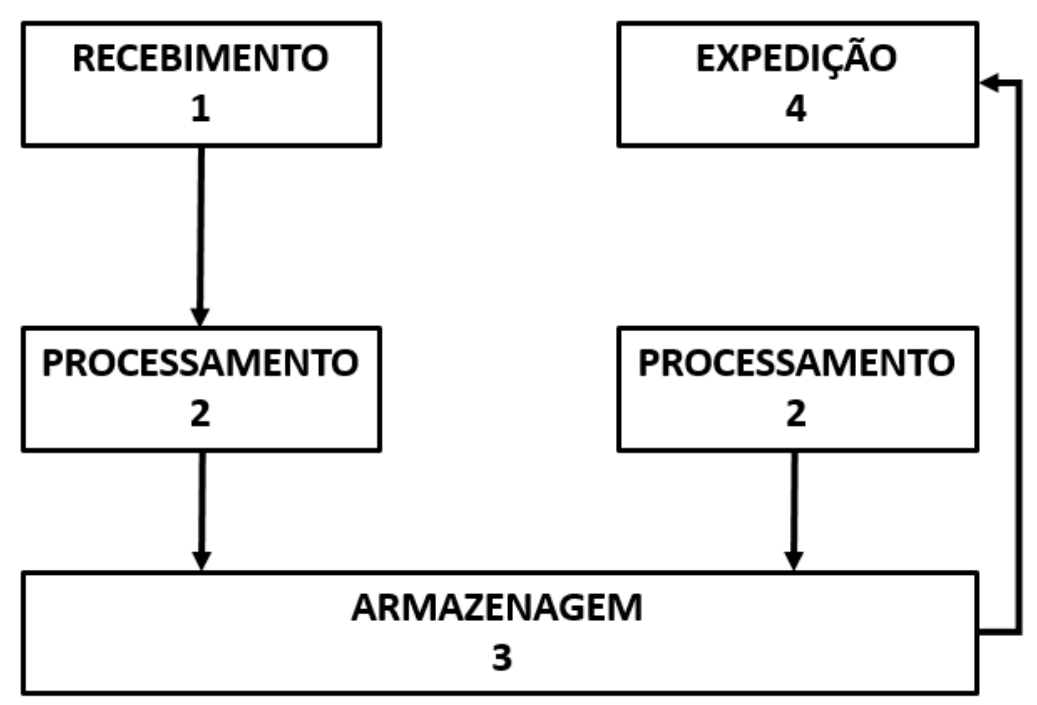

Figura 5 - Layout do CD em estudo.

Fonte: Dos autores.

Tendo ciência de como é o funcionamento desse centro de distribuição, foram buscados dados referentes às mercadorias que transitaram no local em análise nos bancos de dados do sistema, foram realizadas observações e entrevistas, para que se tornasse possível verificar a real influência da implantação do sistema WMS no CD.

A empresa estudada está classificada, segundo a CNAE - Classificação Nacional de Atividades Econômicas elaborada pelo IBGE - Instituto Brasileiro de Geografia e Estatística, como Comércio de Confecções de Artigos do Vestuário e Acessórios. Conforme Parente (2011), o mercado varejista vem assumindo uma importante posição e vem crescendo e se destacando no panorama brasileiro e mundial. À medida que as pequenas empresas varejistas vão se expandindo, passam a adotar tecnologias de informação e de gestão cada vez mais avançadas, desempenhando assim um papel cada vez mais importante na crescente modernização do sistema de distribuição e da economia do Brasil.

Parente (2011) argumenta ainda que o varejo é subdividido em Alimentício, Não Alimentício e de Serviço. O varejo de produtos não alimentícios no Brasil, no qual a empresa em estudo se encaixa,

Revista de Administração e Inovação, São Paulo, v. 10, n.4, p.85-109, out./dez. 2013. 
ainda não apresenta seu total desenvolvimento e, com a expectativa do aumento da renda per capita, pode-se inferir que o setor atravessará diversas mudanças.

Essas mudanças vêm ocorrendo em razão do surgimento de novos players de grande peso no mercado internacional - países do sudeste asiático, particularmente a China que tem conduzido ao acirramento da concorrência internacional (Rangel, Silva \& Costa, 2010), forçando a indústria têxtil brasileira a se adaptar e reduzir seus custos.

\section{ANÁLISE DOS RESULTADOS}

Fazendo uma análise global entre o antes e o depois da implantação do sistema WMS, demonstrados nas Figuras 6 e 7, respectivamente, as figuras demonstram as porcentagens de mercadorias para cada lead time, ou seja, quantos dias os produtos ficaram em estoque.

\section{Antes da Implantação}

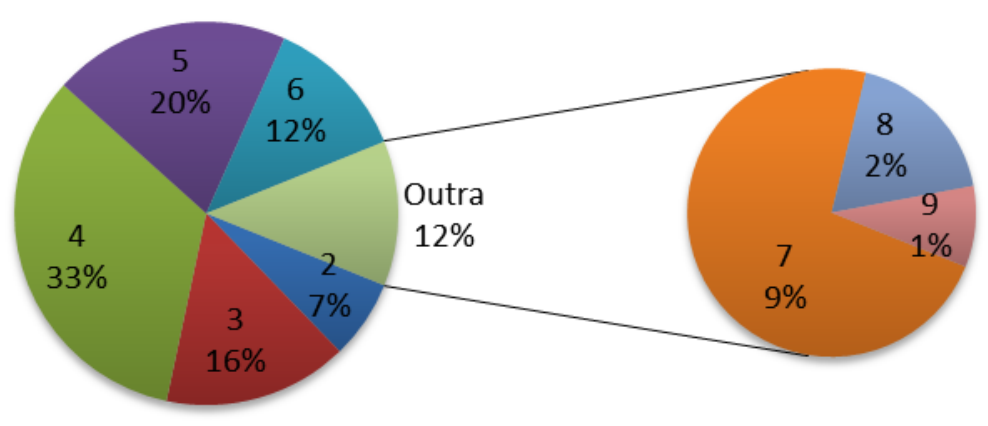

Figura 6 - Percentual de mercadorias X Lead time (dias), antes da implantação do WMS. Fonte: Dos autores.

Percebe-se, de acordo com a Figura 6, que antes da implantação do sistema $W M S, 33 \%$ das mercadorias do centro de distribuição em estudo mantiveram um lead time de 4 dias e que apenas $1 \%$ das mercadorias teve um lead time de 9 dias.

Revista de Administração e Inovação, São Paulo, v. 10, n.4, p. 85-109, out./dez. 2013. 


\section{Depois da Implantação}

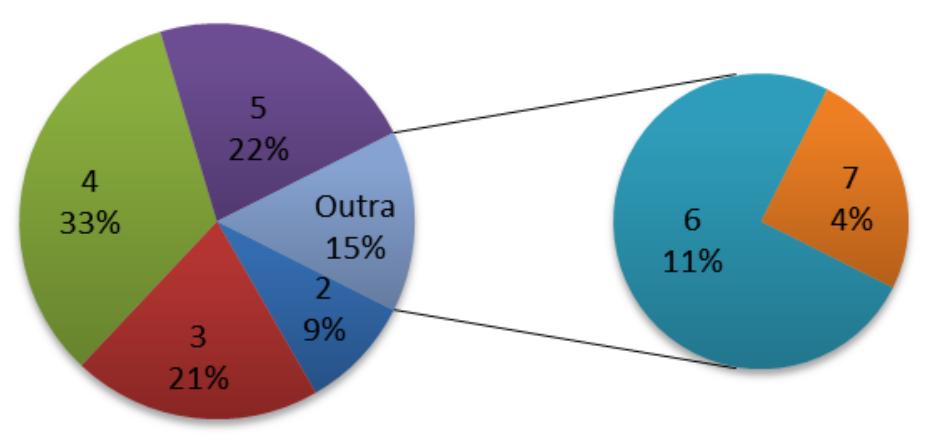

Figura 7 - Percentual de mercadorias X Lead time (dias), após a implantação do WMS.

Fonte: Dos autores.

Depois da implantação do sistema WMS no CD em estudo verificou-se que a quantidade de mercadorias com o lead time de 4 dias se manteve em 33\% e que o lead time máximo foi de 7 dias contra 9 dias antes da implantação do sistema.

Alem disso, pode-se inferir que:

$\checkmark \quad$ Lead time de 2 dias aumentou em 2 pontos percentuais;

$\checkmark \quad$ Lead time de 3 dias aumentou em 5 pontos percentuais;

$\checkmark$ Lead time de 5 dias aumentou em 2 pontos percentuais;

$\checkmark \quad$ Lead time de 6 dias diminuiu em 1 ponto percentual;

Lead time de 7 dias diminuiu em 5 pontos percentuais;

Na Figura 8, pode-se analisar a diminuição do lead time médio das mercadorias analisadas nesta pesquisa, observa-se que a diminuição do primeiro mês da implantação até o último mês analisado foi de aproximadamente $24 \%$, mostrando assim que o sistema implantado trouxe resultados positivos, como o esperado. 


\section{Lead time médio após implantação do WMS}

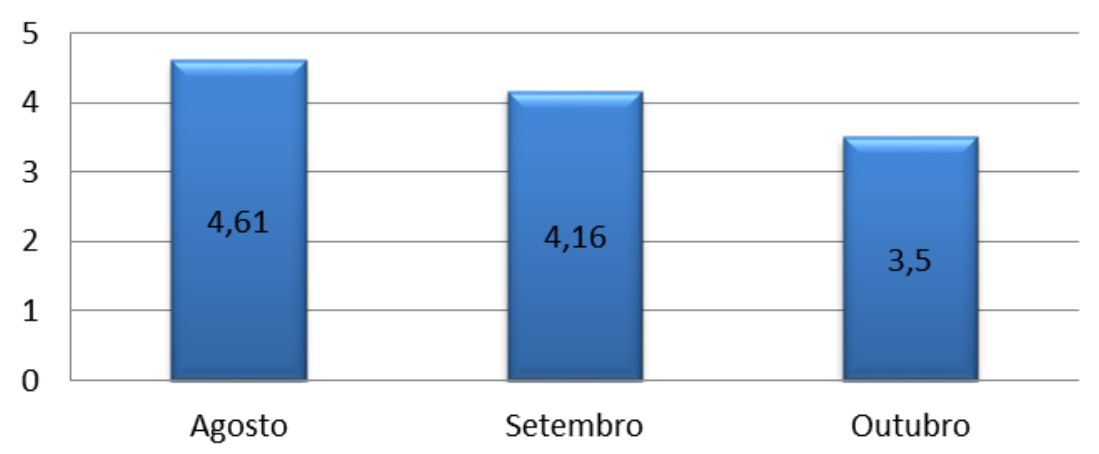

Figura 8 - Lead time médio (dias) X Mês.

Fonte: Dos autores.

Após a implantação do WMS foi possível notar diferenças positivas nas atitudes da equipe gestora no que tange à forma de cobrança, à gestão das pessoas, à medição da produtividade e ao gerenciamento das mercadorias. Foi percebido que os líderes, encarregados e supervisores sentiram-se mais à vontade em utilizar a ferramenta $W M S$ em vez de utilizar o SAP, já que, como pode ser observado, na Figura 9, a medição da produção do CD é feita de forma simples e ágil por meio do sistema WMS.

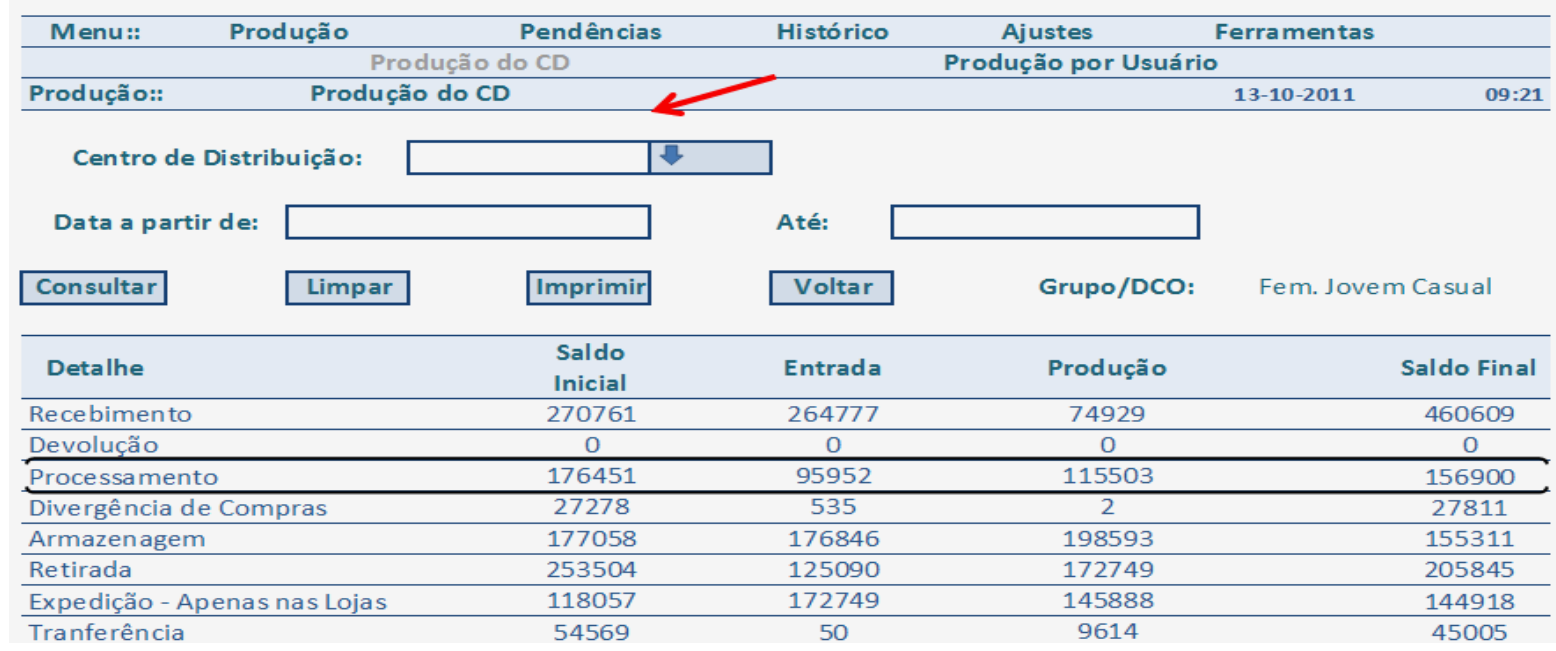

Figura 9 - Consulta da Produção do CD (sistema WMS).

Fonte: Adaptado do sistema WMS.

Também foi possível notar que o acompanhamento das mercadorias que circulam no CD se tornou mais ágil, fácil e é uma atitude que se tornou frequente entre a equipe gestora, uma vez que o 
sistema WMS possibilita esse tipo de gerenciamento. Para tanto utiliza-se a tela do WMS representada pela Figura 10.

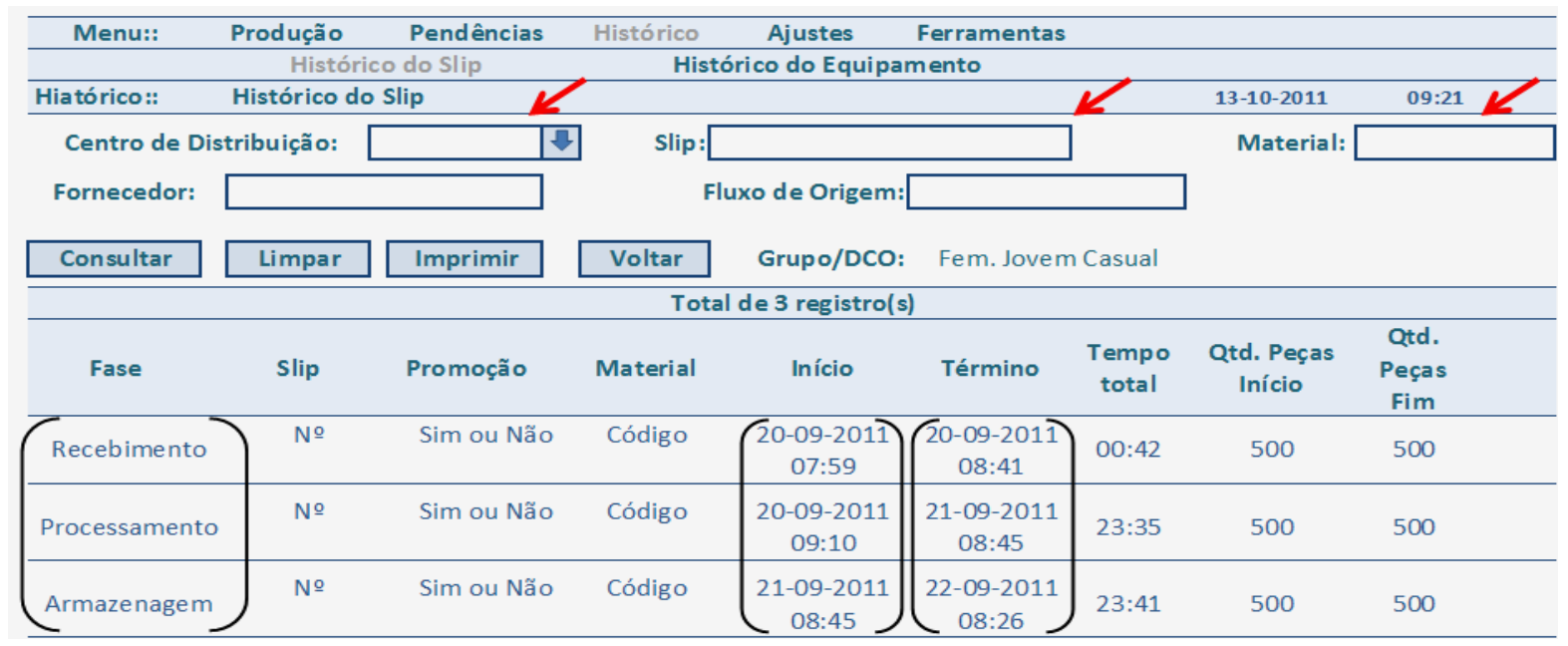

Figura 10 - Histórico das mercadorias por Slip (sistema WMS).

Fonte: Adaptado do sistema WMS.

O gerente, o qual foi entrevistado, também utiliza o sistema WMS para acompanhar o funcionamento do $\mathrm{CD}$, principalmente gerenciando o giro de mercadoria, as quantidades processadas e enviadas para as lojas, para que dessa forma as metas estabelecidas pelos gerentes de operações logísticas sejam atendidas. Para tanto as duas principais telas para esse monitoramento são as apresentadas nas Figuras 9 e 10.

\section{CONCLUSÕES E RECOMENDAÇÕES}

A implantação de um sistema como o WMS é de fundamental importância para o bom funcionamento de estruturas como centros de distribuição, visto que a gestão dessas estruturas é complexa e deve ser realizada com a utilização de sistemas específicos para esses ambientes. Foi observado neste estudo que, a partir da implantação do WMS na organização, houve uma significativa melhora na gestão de todo o $\mathrm{CD}$, principalmente na gestão das mercadorias. Ficou evidenciada a redução do lead time das mercadorias, o qual estava em níveis altos, trazendo-o para próximo do desejado. Sendo assim, o sistema atingiu seu principal objetivo, que era o de reduzir o lead time das mercadorias na gestão do CD. Um dos principais benefícios alcançados com a implantação de sistemas de gerenciamento, como o WMS, é a otimização trazida por esses sistemas no tocante a informações e 
a materiais presentes nos centros de distribuição, o que proporciona um maior controle das operações dessas estruturas.

Por meio das análises feitas dos dados obtidos na pesquisa realizada no $\mathrm{CD}$, foi visto que o sistema WMS implantado na empresa em estudo desempenhou as funções esperadas, auxiliando os gestores do CD nas tomadas de decisão, gestão de pessoas, mercadorias e processos de forma mais ágil e simples que o sistema já existente, o SAP.

Entretanto, é verdade que nenhum sistema funciona bem se os seres humanos que o operam não estiverem comprometidos em usá-lo da forma correta. Assim sendo, o bom preparo e treinamento das pessoas, e também o comprometimento delas, é peça fundamental para o sucesso ou fracasso da implementação de qualquer mudança na organização. Como proposta de trabalhos futuros, cabe o aprofundamento do estudo na área abordada por este trabalho, tendo em vista que as pesquisas neste campo ainda não estão totalmente desenvolvidas e só a partir destas é que melhorias podem ser trazidas aos ambientes de trabalho tornando-os muito mais dinâmicos e versáteis.

\section{REFERÊNCIAS}

Ajayi, I. A \& Omirin, F. F. (2007).The Use of Management Information Systems (MIS) in Decision Making In The South-West Nigerian Universities. Educational Research and Review. Vol. 2 (5), pp. 109-116.

Banzato, E. (2011). Sistemas de Controle e Gerenciamento do Armazém (WMS). Recuperado em 20 Out. 2011 de http://www.guialog.com.br/ARTIGO261.htm

Barbosa, G. R., \& Almeida, A. T. (2002). Sistemas de apoio a decisão sob o enfoque de profissionais de TI e de decisores. XXII ENEGEP. Paraná: Curitiba.

Batista, E. O. (2004). Sistema de Informação: o uso consciente da tecnologia para o gerenciamento. São Paulo: Saraiva,.

Carmo, V. B., \& Pontes, C. C. C. (1999). Sistemas de Informações Gerenciais para programa de qualidade total em pequenas empresas da região de Campinas*. Ci. Inf., Brasília, v. 28, n. 1, p. 4958.

Colangelo Filho, L. (2001). Implantação de Sistemas ERP (Enterprise Resource Planning): um enfoque de logo prazo. São Paulo: Atlas.

Davenport, T. H. (1998). Putting the Enterprise into the Enterprise System. Harvard Business Review. Vol. 75, p. $121-131$.

Revista de Administração e Inovação, São Paulo, v. 10, n.4, p. 85-109, out./dez. 2013. 
Davenport, T. H., \& Prusak, L. Ecologia da Informação: porque só a tecnologia não basta para o sucesso na era da informação. Tradução: Bernadette Siqueira Brandão. São Paulo: Futura,

Davenport, T. H., \& Prusak, L. (2002). Conhecimento Empresarial: como as organizações gerenciam o seu capital intelectual. Tradução: Lenke Peres. Rio de Janeiro: Elsevier, 2003.

Denzin, N. K., \& Lincoln, Y. S. (2006). O Planejamento da Pesquisa Qualitativa: teorias e abordagens. Porto Alegre, Artmed Bookman.

Favoretto, F. (2012). Administração de estoques: diferentes formas de medição da acuracidade. Produto \& Produção, vol 13, n.02, pp. 95-105.

Garcia, D. P., Freitas, L. A. A., Glugovskis, T. O. \& Albuquerque, J. P. A. (2009). Importância do Processo Decisório na Implementação de um Sistema Integrado (ERP) e seus Impactos na Organização: um estudo de caso. XVI SIMPEP: São Paulo.

Gil, A. C. (2009). Como elaborar projetos de pesquisa. São Paulo: Atlas.

Kahraman, C., Kaya, I., \& Çevikcan, E. (2011). Intelligence decision systems in enterprise information management. Journal of Enterprise Information Management, Vol. $24 \mathrm{~N}^{\mathrm{o}}$ 4, pp.360 379.

Kamaruddin, M., Razali, R., \& Deraman, A. (2011). Critical Success Factors of Executive Information Systems Development for Education Management. A Preliminary Investigation. International Conference on Electrical Engineering and Informatics. Indonesia: Bangdun.

Karim, A. J. (2011). The Significance of Management Information Systems for Enhancing Strategic and Tactical Planning. Journal of Information Systems and Technology Management. Vol. 8, $\mathrm{N}^{\mathrm{o}} 2$, p. $459-470$.

Lacerda, L. (2000). Armazenagem Estratégica: analisando novos conceitos. Rio de Janeiro: ILOS.

Laudon, K. C., \& Laudon, J. P. (2007). Sistemas de informações gerenciais. São Paulo: Pearson Prentice Hall.

Leal, G. C. L., Fleming, M., Shinzato, A. A., Soares, J. M., \& Moretti, I. C. (2010). Proposta de um Sistema de Informação para controle de não conformidade em uma indústria do setor vestuário. XVIII SIMPEP. São Paulo: Bauru.

Ma, X., \& Liu, T. (2011). The Application of Wi-Fi RTLS in Automatic Warehouse Management System. International Conference on Automation and Logistics. China: Chongqing.

Machado, A.G.C., \& Moraes, W.F.A. (2011). Tecnologia de informação e customização em massa: evidências na indústria de transformação. RAI - Revista de Administração e Inovação. v. 8, n. 2, p. 190-215.

Oliveira, D. P. R. (2009). Administração de Processos: conceitos, metodologia e prática. São Paulo: Atlas.

Revista de Administração e Inovação, São Paulo, v. 10, n.4, p.85-109, out./dez. 2013. 
Oliveira, D. P. R. (1999). Sistemas de Informações Gerenciais: estratégicas, táticas e operacionais. São Paulo: Atlas.

Parente, J. (2011). Varejo no Brasil: gestão e estratégia. São Paulo: Atlas.

Rangel, A.S., Silva, M.M., \& Costa, B.K. (2010). Competitividade da Indústria Têxtil Brasileira. RAI - Revista de Administração e Inovação. v. 7, n. 1, p. 151-174.

Rezende, D. A. (2005). Engenharia de software e sistemas de informação. Rio de Janeiro: Brasport.

Ribeiro, P. C. C., Silva, L. A. F., \& Benvenuto, S. R. S. (2006). O uso de tecnologia da informação em serviços de armazenagem. Produção, v.16, $n^{o} 3, p$. 526-537.

Rodrigues, G. G., \& Pizzolato, N. D. (2003, Outubro). Centros de Distribuição: armazenagem estratégica. XXIII ENEGEP, Minas Gerais: Ouro Preto.

Russo, M. (2010). Fundamentos em Biblioteconomia e Ciência da Informação. Rio de Janeiro: Epapers Serviços Editoriais.

Slack, N., Chambers, S., \& Johnston, R. (2009). Administração da Produção. São Paulo: Atlas.

Silva, G. N. (2010). Jogos de Licitações: o estado da arte no Brasil. Rio de Janeiro: Biblioteca24horas.

Silva, M. A., Sousa, A. C. A. P., \& Hékis, H. R. (2011). Análises das práticas de gestão da informação de um hospital: um estudo de caso. XVIII SIMPEP. São Paulo: Bauru.

Siqueira, M. C. (2005). Gestão Estratégica da Informação. Rio de Janeiro: Brasport.

Souza, C. A. (2000). Sistemas Integrados de Gestão Empresarial: estudos de caso de Implementação de Sistemas ERP. Dissertação de Mestrado. São Paulo: FEA-USP.

Stair, R. M., \& Reynolds, G. W. (2002). Princípios de Sistemas de Informação. Rio de Janeiro: LTC.

Stal, E., \& Morganti, F. (2011). Multinacionais brasileiras em tecnologia de informação: produção de software e tercerização de serviços. RAI - Revista de Administração e Inovação. v. 8, n. 4, p. 182-205.

Sucupira, C. (2011). Gestão de Depósitos e Centros de Distribuição através dos Softwares WMS. Recuperado em 21 Out. 2011 de http://www.cezarsucupira.com.br/artigos111.htm

Tan, L., \& Dong, L. (2011). The design of web dynpro java based Warehouse Management System. College of Computer and Information Engineering. China: Nanchang.

Tsai, B. (2008). The Impact of Enterprise Resource Planning Systems on the Efficiency of Taiwanese Firms. IEEE Asia-Pacific Services Computing Conference.

Turban, E., McLean, E., \& Wetherbe, J. (2004). Tecnologia da Informação para Gestão: transformando os negócios na economia digital. Porto Alegre: Bookman.

Revista de Administração e Inovação, São Paulo, v. 10, n.4, p. 85-109, out./dez. 2013. 


\title{
INFORMATION SYSTEM: BENEFITS REALIZED THROUGH THE IMPLEMENTATION OF A WMS SYSTEM IN A DISTRIBUTION CENTER OF TEXTILE INDUSTRY IN NATAL / BRAZIL
}

\begin{abstract}
The information systems (IS) have been widely used in organizations for competitive advantage, helping managers in their decision making. One of IS that manages efficiently and effectively a distribution center (DC) is called Warehouse Management System - WMS. This manuscript aims to describe the general improvements stemming from the implementation of a management system DC, focusing on the area of processing of goods for a large company in the textile sector in Natal/Brazil. This study also aims to examine the flow of goods and analyze the current management information system of the company studied. As a result there has been a reduction in lead time of goods by $24 \%$, increased employee productivity and improved management of DC. Another highlight was the elimination of pre-determined locations for goods, optimizing the process and displacement of employees.
\end{abstract}

Keywords: Management Information System; WMS; Distribution Center.

Data do recebimento do artigo: 07/07/2012

Data do aceite de publicação: 05/07/2013

Revista de Administração e Inovação, São Paulo, v. 10, n.4, p.85-109, out./dez. 2013. 